\title{
O IEA da USP: engajamentos ${ }^{*}$
}

CÉSAR ADES

$\mathrm{P}$ ETER Goddard, ao apresentar o Instituto de Estudos Avançados de Princeton, escreve, retomando a caracterização de Abraham Flexner, que seu Instituto continua "pequeno e flexível”. Poderíamos aproveitar a fórmula, talvez com mais propriedade, para o IEA da USP, acrescentando que pequeno e valente. Criado há 25 anos com um entusiasmo que transparece nos textos

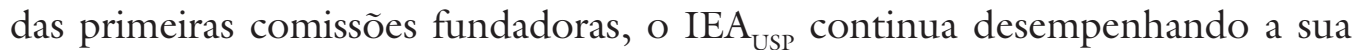
função de aproximar pesquisadores e de discutir perspectivas e ideias pertinentes para a Universidade e para o país. Ele se define a partir de seus engajamentos (por isso a inclusão da palavra no título): um engajamento na causa do conhecimento e da Universidade, mas também um engajamento nas questões sociais, a responsabilidade de participar.

O lema do Instituto de Estudos Avançados Peter Wall do Canadá, “Where converging minds freely explore", capta bem duas das características de atuação de qualquer IEA: proporcionar um contexto para o encontro de pessoas com formações e ideias diferentes a permitir que o pensamento, sem perder a necessária especialização, saia livremente em direção a temáticas novas, encare o não convencional como ponto de partida.

Essas ideias são antigas e recentes. Remontam à tradição de busca do conhecimento em grupos e ambientes reservados ( talvez tão remotas quanto Aristóteles e o liceu). Têm sua imagem arquetípica no IEA de Princeton ou do Wissenchaftskolleg de Berlim. Todos pensam em Princeton, e em Einstein e outros dos ilustres visitantes, quando vem à tona o assunto IEA. Mas há, na ideia de IEA, uma modernidade notável. Na reunião de 2010 de 32 Institutos de Estudos Avançados de todas as regiões do mundo, realizada em Freiburg, na AlbertLudwigs-Universität, verifiquei com surpresa ser o nosso IEA o segundo mais antigo, depois do Stanford Humanities Center, fundado em 1980, seguido pelo Peter Wall Institute for Advanced Studies (Canadá, 1991). Numa segunda leva, vinham, entre outros, o Collegium Helveticum (Suíça, 1997), e o Stellenbosch

* Apresento aqui anotações seletivas e pessoais a respeito do momento do Instituto que eu pude acompanhar, como diretor. Nem sempre registrei, junto à menção dos eventos realizados, as parcerias com outras instituições da USP e de fora, foram muitas e sempre essenciais, e nem pude fazer justiça a todos os que contribuíram e contribuem para a vida do Instituto. Agradecimentos vão para os vice-diretores Hernan Chaimovich e Luiz Roberto Giogetti Britto, para os membros do Conselho Deliberativo, para todos os pesquisadores do IEA-USP e, com reconhecimento especial, para Marilda Gifalli, Mauro Bellesa e Tizuko Terezinha Sakamoto Imamura, a Fátima Moreno, e ao pessoal todo do IEA que sempre arregaçou as mangas. 
Institute for Advanced Study (África do Sul, 1999); numa terceira, o próprio Freiburg Institute for Advanced Studies (Alemanha) 2007, o Réseau Français des Instituts d'Études Avancées (2007) e, recém-fundado, o Centro de Estudos Avançados da Unicamp (2010).

Este levantamento mostra em que medida era pioneira a iniciativa de criação do IEA $A_{\text {USp }}$. Mostra também a existência de uma demanda especial para centros integradores de ciência avançada dentro da Universidade de hoje. Uma fonte de demanda é o grande aumento da produção científica mundial que estabelece critérios mais agudos de qualidade e que põe um valor especial no conhecimento criativo capaz de destacar-se no mar de publicações que saem a cada ano em cada área. Além disso, há de se levar em conta o aumento das interfaces entre as áreas tradicionais de ciência, um movimento de interpenetração que origina, inclusive, novos campos de pesquisa. Nunca a interdisciplinaridade ou transdisciplinaridade $^{2}$ tem sido tão concretamente experimentada. Na psicologia, que é meu campo de estudo, os conhecimentos do funcionamento do cérebro que técnicas novas de exame proporcionam têm mexido com as concepções correntes a respeito de cognição e emoção e têm gerado investigações em que ambos os aspectos, o fisiológico e o comportamental, entram num contexto em que linguagens e técnicas se integram. Os IEA proporcionam um espaço apropriado para essa experimentação conceitual inovadora e podem exercer o papel aglutinador de que necessita a nova Universidade como forma de equilibrar a tendência inevitável à especialização.

No caso do IEA $_{\text {USP, }}$ como dos outros IEA brasileiros, o desafio é o da inserção no momento atual do desenvolvimento científico do país e do mundo. A ciência brasileira se encontra num momento de crescimento inédito ${ }^{3}$ que nos torna interlocutores interessantes; não somos mais apenas consumidores do conhecimento produzido em outros centros. Novas estratégias são requeridas. Cooperações internacionais são o sinal de uma maneira de fazer ciência em que se transcende um modelo mais antigo de produção. Sediamos, por exemplo, no ano passado, no IEA $\mathrm{USP}_{\mathrm{SP}}$ o colóquio Saint-Hilaire 2010, primeira jornada de cooperação científica franco-brasileira em Ciências Humanas e Sociais, uma iniciativa da Embaixada Francesa com apoio USP e Capes, que permitirá a publicação de trabalhos efetuados por equipes franco-brasileiras. Nessa iniciativa foi relevante o empenho de Hervé Therry, do IEA ${ }_{\text {Usp, }}$ que inclusive sugeriu que o nome de Auguste de Saint-Hilaire, naturalista francês que tão extensamente viajou pelo Brasil, fosse dado ao programa. A instalação, também em 2010 do Instituto de Estudos Brasil-Europa, subvencionado pela União Europeia, com participação da USP, é outro caso digno de nota. A USP, por meio de sua ViceReitoria Executiva de Relações Internacionais, está lançando bases de interna-

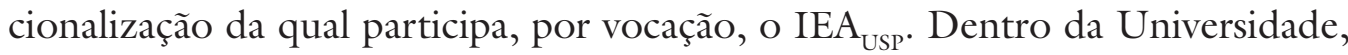
para nós, o desafio é participar do desenvolvimento de uma Universidade do porte e da importância da USP, ${ }^{4}$ não como um Instituto à parte, mas como lugar de convergência e inovação. 


\section{Saber avançado}

Esperam-se dos IEA avanços notáveis no conhecimento, mais pelo lado teórico e conceitual do que pelo lado da pesquisa empírica. É a inovação que interessa, em ideias e modelos de interpretação. No imaginário dos IEA está uma epistemologia de risco e livre exploração, a concepção de que fazer ciência não consiste apenas na aplicação de um paradigma, mas na sua extensão a campos diferentes (até mesmo fora de seu estrito domínio, caso em que entra a intenção interdisciplinar) ou no limite sua colocação em xeque. Uma (certa) desordem criativa, inclusive a que decorre do confronto de ideias divergentes, é bem-vinda. Temos tido esse espírito em grupos do Instituto, até num deles recentemente estabelecido em que a intenção está no próprio título (grupo de Astrofísica $\mathrm{Nu}$ clear Não Convencional), também está no trabalho mais tradicional do grupo de Lógica e Teoria da Ciência, feito em torno da questão das lógicas não clássicas, inspirado no pensamento de Newton da Costa.

Aspectos novos e surpreendentes da ciência têm sido apresentados no IEA $_{\text {USP }}$, dentro do ciclo "Ciência Avançada", dedicado a cientistas brasileiros, inaugurado este ano como parte das comemorações dos 25 anos. Já tivemos as palestras de Miguel Nicolelis (Duke, EUA/Instituto Internacional de Neurociências, Natal), "Computando com populações neurais"; João E. Steiner (USP), "Buracos negros: sementes ou cemitérios de galáxias?; 6 Eleonora C. Albano (Unicamp), "A emergência da sílaba nas línguas orais: ontogênese ou filogênese?"; Sérgio Danilo Pena (UFMG), "Estrutura e formação genética do povo brasileiro"; 8 Roberto Lent (UFRJ), "Quantos neurônios você tem? Alguns dogmas da neurociências sob revisão"; e terá prosseguimento com as de Didier Demolin (USP e Gipsa-lab, Grenoble), "Comunicação animal e linguagem humana"; Hugo Aguirre Armelin (Instituto Butantã), "Controle do ciclo celular: Da molécula à célula"; Marina Massimi (USP, Ribeirão Preto), "Saberes psicológicos na história da cultura brasileira".

Pesquisadores estrangeiros têm trazido informação e questionamentos sobre áreas modernas de ciência e sociedade. Cito: Ignacy Sachs (École des Hautes Études des Sciênces Sociales, França), Hugh Lacey (Swarthmore College, EUA), Jerry Hogan (Universidade de Toronto, Canadá), Pier Luigi Luisi (Universidade de Roma III, Itália), Stanislas Dehaene, Roger Chartier (Collège de France), Marcelo Gleiser (Darthmouth College, EUA), John W. Wenzel (State University, Ohio, EUA), Vincent Fourcassié (Université Paul Sabatier, França), Robert Trivers (Rutgers University, EUA), Antonio Novoa (Universidade de Lisboa), Lorenzo Agar Corbinos (Universidade do Chile), Peter Burke (Universidade de Cambridge, UK), Martha Schteingart (Colégio de México), Tom Wenseleers (Universidade de Leuven, Bélgica), Sheila Jasanoff (Universidade de Harvard, EUA), Philippe Rochat (Universidade de Emory, EUA), Carlos Bertulani (Texas A\&M University, EUA), Francisco Javier Guevara Martinez (Universidade Autônoma de Puebla, México). 
Impressiona o quanto se aprende numa palestra, mesmo quando se trata de um assunto a respeito do qual não se tem competência, o proveito talvez decorra justamente de ser um assunto novo e das convergências inesperadas com conhecimentos prévios. Os palestrantes abrem a sua oficina de pesquisa e fazem que se participe das conquistas e também das incertezas em temas variados que vão das características que tornam a vida um fenômeno emergente às propostas de reforma do sistema político brasileiro; das bases cerebrais da intuição matemática aos problemas éticos do uso de seres humanos em pesquisas médicas. Também suscitam ideias a respeito do que poderá ser feito. Em recente palestra no IEA $_{\text {usp }}$, Russell Mittermeier, presidente da Conservation International e primatologista de renome (tinha sido condecorado no mesmo dia, com a medalha João Pedro Cardoso do Governo do Estado de São Paulo), mostrou, por meio de números e casos de sua extensa experiência, a situação da conservação da biodiversidade e indicou possíveis caminhos estratégicos. Fiquei estimulado pela sua análise, feita de maneira positiva, do caso brasileiro e pela sua conviç̧ão de que o Brasil desempenhará um papel de liderança como país megadiverso e como modelo de defesa da natureza, na década mundial da biodiversidade que agora se abre. Vieram ideias de projetos de estudo, no futuro, para o Instituto.

Praticamente todos os eventos produzidos ou apoiados pelo IEA $_{\text {USP }}$ são transmitidos ao vivo, abrindo espaço para uma audiência virtual. As perguntas que vêm de longe mostram o quanto pode ampliar-se a sala de conferências e democratizam o debate: o saber tem de sair dos seus círculos de giz. Gravamos quase todas as palestras, mesas-redondas, congressos e outras reuniões, os registros são editados e conservados numa midiateca acessível a quem entre no site do IEA. Uma vantagem imediata é permitir a consulta, outra é a constituição, ao longo dos anos, de um arquivo muito rico a respeito do pensamento da Universidade e da história de nossa cultura. Estamos agora digitalizando um primeiro conjunto de gravações de áudio analógicas feitas há mais de duas décadas, acredito que atrairão bastante interesse quando postas à disposição on-line.

Aproveito para enfatizar a relevância da comunicação, como parte do projeto de um IEA: não apenas a comunicação essencial dirigida a audiências restritas, mas uma comunicação que visa dar visibilidade e despertar interesse, num segmento maior da população. A produção do boletim Contato, a reformulação do site na internet, ${ }^{10}$ a implementação de projetos para a publicação de material institucional têm sido algumas das atribuições da seção de comunicação do instituto.

\section{Público e estratégico}

Proveniente do arquétipo princetoniano é a ideia de que a busca realizada nos IEA deve ser livre, inclusive das demandas sociais por aplicação. No seu famoso artigo de 1939, "The usefulness of useless knowledge", Flexner ${ }^{11}$ defende o conhecimento obtido a partir de um movimento intelectual livre e mostra como grandes contribuições na física e na matemática e em outros campos ti- 
veram por origem a curiosidade e o desejo de encontrar princípios que são as motivações científicas básicas. É um belo artigo que merece ser sempre discutido quando examinadas as finalidades da Universidade.

O Instituto também tomou seu impulso inicial nesse objetivo de conhecimento puro. Mas, e é essa uma característica de seu pioneirismo, optou desde cedo pela reflexão acadêmica aplicada a problemas de relevância social. Vemos implícita essa opção no quarto item das atribuições estatutárias do primeiro IEA $_{\text {USP }}$ " "incentivar estudos sobre políticas de desenvolvimento da ciência, da tecnologia e da cultura em geral, bem como sobre o uso social do conbecimento, tendo em conta a melhor articulação entre a Universidade e a sociedade" (grifo meu).

José Jeremias de Oliveira Filho, participante ativo dos primórdios do IEA usp, contou-me que, numa das reuniões da comissão que pensou o Instituto, José Goldemberg teria opinado: “o IEA tem de discutir políticas públicas!”. Na época, Jeremias foi contra, teve medo que o IEA pudesse ser influenciado por partidos e grupos políticos. Declarou recentemente, rememorando: “A ideia de políticas públicas acabou sendo um sucesso, o IEA em nenhum momento foi instrumentalizado, todas as tentativas foram malsucedidas". ${ }^{12} \mathrm{O}$ IEA $_{\text {UsP }}$ permanece um território não "instrumentalizado". Dos seminários sobre "O congresso nacional no contexto do presidencialismo de coalizão" (2010) e "Reforma política: sistema eleitoral em debate" (2011), coordenados por José Álvaro Moisés, participaram políticos de ideias e partidos diferentes sem que a discussão deixasse por um momento de se pautar pela liberdade e pela intenção acadêmica.

A discussão das políticas públicas se vale, como no caso da discussão científica, da abordagem interdisciplinar e da livre exploração: mudam o tema e o tipo de análise, o pano de fundo é estratégico, aproveitam-se informações diversas para avaliar um estado de coisas e para guiar uma ação institucional. Parafraseando Flexner, busca-se the usefulness of useful ideas, aproveita-se o jeito científico para examinar questões sociais.

Produzir mudanças sociais, diretamente, não é a meta, isso cabe a quem dispõe do cargo e do poder; trata-se de elaborar propostas e explorar o diálogo com as instituições. Há um interesse crescente, em setores do poder público, pelo debate com a academia em torno dos grandes assuntos, como clima, nutrição, violência, educação, pobreza. Emblemática é a afirmação, num texto recente da SBPC e da Academia Brasileira de Ciências sobre o Código Florestal, de que decisões do poder público a respeito dessa questão têm de ser tomadas à luz do conhecimento científico e tecnológico vigente. ${ }^{13} \mathrm{E}$ é nessa interface que se situa a análise e o debate em sociedades científicas e em Institutos de Estudos Avançados.

Não há consenso a respeito disso. São poucos os IEA internacionais que colocam como meta essencial a discussão dos grandes assuntos públicos. Frick, Dose e Ertel não a mencionam, no mapeamento que efetuaram apenas indicam 
que "alguns Institutos enfatizam o seu papel como think tanks públicos e dedicam bastante empenho ao planejamento de eventos de maior alcance público". Há quem pense que assuntos sociais devam ser tratados em instâncias outras, restringindo-se o papel dos IEA à ciência enquanto tal. Pensamos diferente-

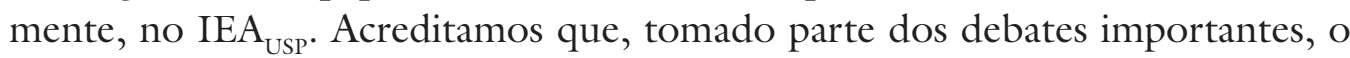
Instituto atende à vocação da Universidade de pensar o país e de contribuir para as condições de justiça, bem-estar e progresso social. É significativo que, quando foi organizado no IEA $\mathrm{USP}_{\mathrm{UP}}$ um debate com os oito candidatos à reitoria da USP, em 8 de outubro de 2009, tenha sido justamente escolhido como tema de reflexão: "A USP e a sociedade". ${ }^{14}$ Um interesse similar por problemas estratégicos está presente na trajetória do Centro de Estudos Avançados Multidisciplinares da UnB e, com origem mais recente, no Centro de Estudos Avançados da Unicamp.

\section{Entre a ciência e a política pública}

Foi muita a produção do Instituto dentro da vertente das políticas públicas e do pensamento estratégico. Cito o emblemático projeto Floram que, desenvolvido em 1990, teve como foco o florestamento e o sequestro de carbono e foi precursor em relação às preocupações ambientais de hoje. ${ }^{15}$ Uma dissertação de mestrado defendida na USP a respeito dos vinte anos do projeto Floram indica serem suas propostas ainda reconhecidas como válidas como forma de assegurar uma economia de baixo carbono, e que "sua plena implementação viabilizaria o desenvolvimento econômico, ambiental e social, uma das premissas do Projeto". ${ }^{16}$

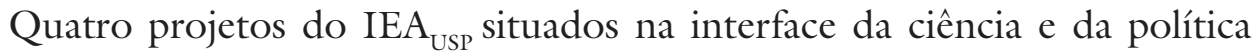
pública dão uma ideia da relevância dessa abordagem, eu os tomo nas área de Serviços Ambientais, Meio Ambiente, Saúde e Inovação.

O projeto ${ }^{17}$ do grupo de pesquisa Serviços dos Ecossistemas coloca-se em continuidade com o espírito do projeto Floram pela preocupação com o ambiente e pela colocação de um projeto nacional. Aborda a questão, de primeira relevância, porém pouco conhecida, da polinização. Abelhas e outros polinizadores constituem um fator que influi na biodiversidade e na produção de alimentos, a queda de suas populações é uma ameaça que exige a implantação de novas medidas de manejo. O livro organizado por Vera Lucia ImperatrizFonseca, Dora Ann Lange Canhos, Antonio Mauro Saraiva e Denise de Araujo Alves, Polinizadores no Brasil: contribuição e perspectivas para a biodiversidade, uso sustentável, conservação e serviços ambientais, a ser publicado em breve, atende a essa necessidade e promete ser um marco na área. Nele a pesquisa e o pensamento estratégico se combinam: são 84 pesquisadores de quarenta instituições situadas em muitos Estados do Brasil que trazem resultados científicos; nos capítulos finais do livro, há uma proposta de gestão que poderá embasar a política pública para o manejo de polinizadores.

A III Conferência Regional de Mudanças Climáticas, organizada pelo grupo de pesquisa Ciências Ambientais em 2009, abordou a questão da repercus- 
são das alterações do clima na América do Sul, com textos disponíveis em livro on-line do IEA, 2009. ${ }^{18}$ A IV Conferência Regional sobre Mudanças Globais, realizada em 2011, terá os seus textos publicados em livro on-line do $\operatorname{IEA}_{\mathrm{USP}} \mathrm{em}$ 2012. Integram essas conferências instituições de pesquisa, do setor privado e de entidades da sociedade civil que buscam soluções científicas viáveis e socialmente construtivas para os desafios ambientais.

O grupo de Nutrição e Pobreza lida com um tema urgente, o da desnutrição em populações de extrema pobreza em nosso país, a partir de uma abordagem que se marca pela multidisciplinaridade e busca ativa do contato com as populações carentes. Seu livro Desnutrição, pobreza e sofrimento psíquico com contribuições de mais de vinte autores, que acaba de ser publicado pela Edusp, representa o fruto de um esforço pioneiro de pesquisa em que o social, o biológico e o comportamental são tomados com elementos para o diagnóstico e a atuação pública. ${ }^{19}$

O Observatório de Inovação e Competitividade tem se valido de uma articulação com entidades públicas como a Agência Brasileira de Desenvolvimento Industrial e o Centro de Gestão e Estudos Estratégicos e tem sido ativo na elaboração de pesquisas e análises sobre inovação e sociedade. Num de seus estudos, em si inovador, foram comparadas as estratégias de inovação de sete países. ${ }^{20} \mathrm{O}$ Observatório elaborou um amplo projeto de pesquisa que visa à criação de dois índices gerais, um sobre inovação e o outro sobre engenharia, relevantes para a avaliação de mudanças e progressos na área produtiva. O projeto foi aprovado em 2011 pela Pró-Reitoria de Pesquisa dentro do edital dos Núcleos de Apoio à Pesquisa da USP.

\section{Ambiente}

Sem indicar os créditos de parceria (mas certamente reconhecendo-os), exemplifico a produção do Instituto em questões ambientais:

Água (participação do grupo de Ciências Ambientais na rede Waterlat que congrega pesquisadores da América Latina e da Europa dedicados à análise de temas relacionados com a ecologia política da água); clima ("Clima e desenvolvimento: a caminho de Copenhague", simpósio com a participação do ministro britânico de Energia e Mudanças Climáticas Ed Milliband); desenvolvimento sustentável ("Os jovens ante o desafio do desenvolvimento sustentável”, palestra da senadora Marina Silva); energia (ciclo "Pré-sal na USP"); resíduos sólidos (simpósio "Resíduos sólidos urbanos e seus impactos socioambientais"); Amazônia ("A gestão da Amazônia: ações empresariais, políticas públicas: estudos e propostas", "Manejo dos recursos hídricos da bacia Amazônica"); eventos extremos ("Eventos extremos no Brasil: causas e impactos", e o debate "Energia nuclear: do anátema ao diálogo", que, programado antes da ocorrência do acidente da usina nuclear de Fukushima - a partir de livro organizado por José Eli da Veiga -, por coincidência ocorreu logo depois, num momento mais do que oportuno); políticas públicas ("Políticas públicas, territorialidades e participação 
social: diálogos sobre a várzea do Tietê", "O código florestal brasileiro: entre a produção e a conservação ambiental" ${ }^{21}$ ) etc.

Seminários nossos colocam em primeiro plano a intenção estratégica, entre eles o "Colóquio 2010-2020: um Período Promissor para o Brasil? - Homenagem a José Goldemberg", em 2008; ${ }^{22}$ e "Desafios socioambientais para o século XXI - Homenagem a Aziz Ab’Saber”, em 2009.

\section{Humanas e Sociais}

Também exemplifico contribuições na área de Ciências Humanas e Sociais, que tem recebido atenção no Instituto, equilibrando o foco em ciências da natureza.

Grupo Temas Atuais da Educação (ciclo "Sentido formativo das humanidades e das ciências"); grupo Diálogos Interculturais (Seminário internacional sobre contatos e experiências interétnicas); grupo Psicologia Socioambiental (intercâmbio com a Universidade de Puebla, análises comparativas sobre cidades e coletivos sociais); Cátedra Bernardo O'Higgins (coordenador, André Eduardo Aguirre Antúnez: intercâmbio acadêmico em psicologia com a Universidade de La Frontera, Chile); Idosos no Brasil (coordenador, David Braga Jr: ciclo de seminários sobre demografia, saúde, comportamento de idosos); Cátedra Unesco de Educação para a Paz, Direitos Humanos, Democracia e Tolerância (coordenador, Sérgio Adorno: simpósios e palestras entre as quais "La juridicité comme catégorie interculturelle dans le contexte de mondialisation", Étienne Le Roy, Universidade de Paris I, "Genocides and political violence in a new political order”, Marina Calloni, Universidade dos Estudos de Milão-Bicocca).

\section{Polos do IEA}

Lembro-me da surpresa do Sujian Guo, do Fudan Institute for Advanced Studies in the Social Sciences (China), quando viu os números da USP - número de Institutos, número de cursos de graduação e de pós-graduação, número de professores e alunos - e me disse "Eu pensei que a nossa Universidade fosse grande, mas a sua!". Talvez por conta do porte da USP, somos o único IEA no mundo que possui polos em vários campi, uma forma de atender a diferenças em cada um e proporcionar um desenvolvimento distribuído. Nosso primeiro polo, criado em São Carlos, em 1997, a partir de iniciativa e visão do físico (Princeton!) Sérgio Mascarenhas, está em pleno desenvolvimento, inclusive com a perspectiva de construção de uma nova sede. É agora coordenado pelo também físico Roberto Mendonça Faria. O segundo polo, o do campus de Ribeirão Preto, foi inaugurado em 4 de novembro de 2009 , tendo a iniciativa de sua criação contado com o apoio da reitora Suely Vilela. Sob coordenação de Oswaldo Baffa Filho, está tomando impulso, com projetos de estabelecimento de grupos de pesquisa e de cátedras para professores visitantes. Uma infraestrutura mínima de pessoal já foi conseguida, a sede definitiva está em negociação. Uma perspectiva animadora, ainda em discussão, será a implantação do polo IEA-Piracicaba, na Esalq. 


\section{Pensar o Brasil: a revista ESTUDOS AVANÇADOS}

Num dos últimos levantamentos, a revista ESTUDOS AVANÇADOS despontou como a segunda mais consultada (são milhões de consultas) dentre as revistas indexadas pela SciELO, uma posição que sinaliza a sua importância como veículo de ideias. Ela é, como bem coloca o seu editor Alfredo Bosi, uma revista preocupada em "pensar o Brasil, conhecer a fundo o seu presente para ajudar a construir o seu futuro". Águas, Epidemias, Crise Internacional, Teorias Socioambientais, Biotecnologia, São Panlo Hoje têm sido alguns dos temas de seus dossiês recentes, vê-se que a revista sintoniza-se com a linha de reflexão do Instituto centrada em problemas de relevância social. Os dossiês da revista têm sido regularmente vertidos para o inglês, visando a uma leitura internacional. Vejo num futuro próximo a expansão da edição de ESTUDOS AVANÇADOS em inglês e sua transformação fonte de referência importante a respeito de estudos brasileiros.

\section{Grupos de pesquisa}

O Instituto tem trabalhado principalmente por meio de grupos de pesquisa multidisciplinares. Os projetos são estruturados com liberdade pelos coordenadores que escolhem os membros e os temas focais, os grupos decidem e debatem as questões em reuniões periódicas das quais participa um analista de comunicação do Instituto que proporciona apoio de secretaria e infraestrutura. A riqueza dos grupos decorre de sua composição variada e do próprio mecanismo de discussão interna, gerador de ideias.

São grupos dentro de uma ampla subdivisão em Ciências da Natureza e da Vida e Ciências Sociais e Humanas, alguns em fase de término ou de renovação, aqui arrolados com os seus coordenadores: Ciência Ambientais (Wagner Costa Ribeiro); Serviços de Ecossistemas (Vera Lúcia Imperatriz Fonseca); Amazônia em Transformação: História e Perspectivas (Maritta Koch-Weser e José Pedro de Oliveira Costa); Lógica e Teoria da Ciência (Jair Minoro Abe); Filosofia, História e Sociologia da Ciência e da Tecnologia (Pablo Rubén Mariconda); Astrofísica Nuclear Não Convencional (Mahir Saleh Hussein); Observatório de Inovação e Competitividade (Glauco Arbix e Mario Salerno); Nutrição e Pobreza (Ana Lydia Sawaya); Temas Atuais da Educação (Maria Helena Souza Patto); Políticas Públicas, Territorialidades e Sociedade (Neli Aparecida de Mello Théry); Diálogos Interculturais (Sylvia Duarte Dantas); Psicologia Socioambiental (Eda Tassara); e Literatura e Cultura (Alfredo Bosi). O I Workshop Intergrupos, programado para ser realizado em novembro de 2011 , visa intensificar as interações entre pesquisadores.

Tem sido a reivindicação do Instituto ter condições de receber regularmente professores visitantes e colaboradores, tendo inclusive o Instituto influenciado, na sua origem, a criação de bolsas da USP para professores visitantes. As perspectivas de conseguir visitantes e colaboradores parecem agora melhores, a partir do interesse da USP em internacionalizar-se e em receber em seu ambiente especialistas de renome. 


\section{Cursos}

Os IEA têm um perfil diferente, dentre os Institutos da Universidade, não ministram cursos de graduação ou de pós-graduação. Mas cabe-lhes oferecer cursos breves que se enquadram bem na missão de discutir conhecimentos de ponta e da abertura para questões de relevância social. O IEA de Jerusalém oferece, por exemplo, cursos avançados de 4 a 10 dias de duração em matemática, física etc., às vezes coordenados por professores com Prêmio Nobel; cursos fazem parte da rotina do Collège de France.

Embora não contasse com Prêmios Nobel, uma experiência muito bemsucedida, dentro do IEA $_{\mathrm{USP}}$, foi a realização da Escola São Paulo de Estudos Avançados em Dinâmica Fônica, com apoio Fapesp e CNPq, com coordenação geral de Eleonora Albano (Unicamp). ${ }^{23}$ A escola mobilizou professores estrangeiros e brasileiros e teve audiência, bem no espírito do ensino Universitário moderno; acotovelavam-se estudantes de várias nacionalidades.

Outro curso, em nível de pós-graduação, foi o "First Brazil-US biofuels short course: providing interdisciplinary education in biofuels technology" (Rede de Biocombustíveis do Conselho Brasil-EUA de Educação Superior e do IEA, com apoio Fapesp-Bioen e CNPq), ministrado por professores de ambos os países, para estudantes brasileiros e norte-americanos.

"Descobrir a Amazônia, descobrir-se repórter", um curso coordenado em anos sucessivos por Sérgio Gomes e Pedro Ortiz, em parceria com a Oboré Projetos Especiais em Comunicações e Artes, com os Centros de Comunicação Social do Exército e da Aeronáutica e outras instituições, teve como alvo estudantes de graduação de jornalismo da USP e de várias Universidades de São Paulo, que participaram de um ciclo de palestras de alto nível com especialistas e militares sobre a Amazônia.

Menciono ainda o curso "Filosofia e História da Ciência", ministrado por Fernando Tula Molina, da Universidade Nacional de Quilmes (Argentina). ${ }^{24}$

\section{IEA \& Universidade}

Num seminário de 2008, sentaram-se à mesma mesa seis reitores da USP, Suely Vilela, reitora na época, José Goldemberg, Adolfo José Melfi, Antonio Helio Guerra Vieira, Flávio Fava de Moraes e Jacques Marcovitch (quase um quarto de século de gestões) em torno do tema "A USP e as Universidades de pesquisa de classe mundial: prioridades de ação para a próxima década". A reunião coloca, simbolicamente, o papel do IEA na Universidade. Os organizadores do encontro internacional dos IEA em Freiburg distinguiram University Based Institutes of Advanced Study (Ubias), a ser distinguida dos Institutos autônomos como é o de Princeton. Os IEA, no estilo Ubias, se definem em razão da Universidade à qual pertencem.

São vários os níveis de interação Instituto/Universidade. Há a participação de professores da Universidade nos grupos de pesquisa do Instituto e de colegas que são convidados como palestrantes ou para compor mesas de discussão. 
Foram muitas e produtivas as parcerias estabelecidas entre o Instituto e outros Institutos e setores da Universidade (IF, FEA, IB, ICB, IEE, IEB, IP, Sibi e outros) para a realização de simpósios e eventos conjuntos, ou para programas conjuntos com convidados internacionais.

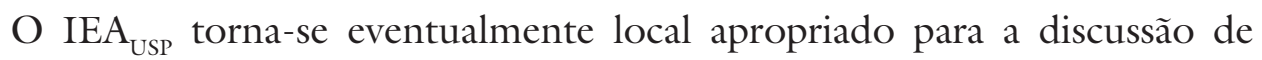
questões institucionais da própria USP, talvez por conta do seu clima de neutralidade e pelo traquejo em organizar debates. Em setembro de 2009, foi realizada uma mesa-redonda com o título sugestivo "A USP precisa mudar", ${ }^{25}$ coordenada por Renato Janine Ribeiro, em que se aproveitaram temas de um ensaio previamente publicado na mídia. O próprio Janine Ribeiro preparou um texto sobre possíveis mudanças no sistema de eleição do reitor que mereceria uma discussão no estilo IEA.

Reuniões produtivas com diretores de Institutos Especializados da USP (entre os quais se inclui o IEA ${ }_{\text {USP }}$ ), Antonio Vargas de Oliveira Figueira (Cena), Claudio Sergio Pannuti (IMT), José Aquiles Baesso Grimoni (então diretor do IEE), José Roberto Machado Cunha da Silva (Cebimar), Maria Ângela Faggin Pereira Leite (IEB), deram origem à redação de um texto revisto pelo atual diretor do IEE, Ildo Luís Sauer, publicado em julho de 2011 no Jornal da USP sobre "Diversidade e Integração na USP" ${ }^{26}$

Recebemos, em setembro, convite do pró-reitor de Pós-Graduação Vahan Agopyan e do pró-reitor adjunto, Arlindo Philippi Júnior, para participar de reunião com os presidentes das comissões de pós-graduação das unidades da USP, em que se discutiria a formulação de um documento da USP a ser apresentado em junho de 2012 na Rio+20. Na reunião, na qual foi relembrada nossa atuação em grandes foros ambientais como o Rio 92, fomos encarregados de coordenar o trabalho da comissão especial que cuidará do projeto.

A inserção USPiana de nosso Instituto está em processo. Contatos foram iniciados com a Pró-Reitoria de Pesquisa e de Cultura e Extensão, na pessoa da pró-reitora Maria Arminda do Nascimento Arruda; Luiz Roberto Giorgetti de Britto tem dado presença ao nosso Instituto no Conselho de Pesquisa junto ao pró-reitor Marco Antônio Zago; estamos em contato e cooperação com o vicereitor Adnei Melges de Andrade (Vice-Reitoria Executiva de Relações Internacionais) e temos mantido diálogo com o vice-reitor Hélio Nogueira da Cruz. Como eu me manifestei, por ocasião de uma reunião dos ex-diretores do IEA com o reitor João Grandino Rodas, o coração do Instituto pulsa no ritmo da USP.

\section{IEA brasileiros}

A ideia de instaurar uma interação maior entre IEA brasileiros provém de visitas recebidas, todas gratas porque traziam notícias das atividades relevantes efetuadas em outros contextos. Além de Adilson de Oliveira, na época diretor do Colégio Brasileiro de Altos Estudos, da UFRJ, recebemos no Instituto Pedro Paulo Funari, diretor do Centro de Estudos Avançados da Unicamp (CEAv), e 
Maurício Alves Loureiro, diretor do Instituto de Estudos Avançados Transdisciplinares da UFMG (Ieat). Tomava-se contato com a natureza diversificada, porém coerente, dos IEA nacionais, era natural que se pensasse em intercâmbios.

Pude participar de reuniões organizados pelo CEAv, em duas oportunidades, no simpósio "Desafios de um Instituto de Estudos Avançados na Universidade Brasileira", em outubro de 2010, do qual também participaram Jacques Marcovitch e o diretor científico da Fapesp, Carlos Henrique de Brito Cruz. A segunda foi o "Simpósio internacional sobre Estudos Avançados-Unicamp" em março de 2011, juntamente com Iris Litt, do Centro de Estudos Avançados de Stanford, Peter Goddard, do IEA de Princeton, e Eliezer Rabinovici, do IEA de Jerusalém, assim como de coordenadores de grupos de estudos do CEAv. Funari e eu participamos juntos do encontro de Freiburg, também em outubro de 2010. Nas duas reuniões estava presente o reitor da Unicamp, Fernando Ferreira Costa.

Também me foi dado participar do Seminário Anual do Ieat 2010 - Retrospectiva e Prospecção, na UFMG, a convite do Maurício Loureiro. Foi bom entrar em contato com os pesquisadores do Ieat e seus temas de pesquisa e interagir com o reitor da UFMG, Clélio Campolina Diniz, presente na ocasião.

Esses contatos resultaram numa reunião de Funari, Loureiro e eu no IEA usp, em junho de 2011 , em que foi decidida a realização do que seria o primeiro workshop de IEA brasileiros, intitulado "Estudos Avançados e Universidade". Desse evento, que ocorrerá em outubro de 2011, participarão cinco Institutos: além dos mencionados, o Instituto Latino-americano de Estudos Avançados e Políticas Públicas (Ilea) da UFRGS e o Centro de Estudos Avançados Multidisciplinares (Ceam) da UnB.

As apresentações serão: Maurício Loureiro (Ieat), "Transdisciplinaridade e excelência: a missão do Ieat na UFMG"; Guillermo Juan Creus (Ilea), "O Instituto Latino-americano de Estudos Avançados e políticas públicas"; Pedro Paulo Funari (CEAv), "Considerações sobre os aspectos estratégicos dos estudos avançados"; Ricardo Caldas (Ceam), "O Ceam e os estudos prospectivos". Eu falarei, olhando longe, a respeito dos "Desafios para os IEA no século XXI". No horizonte, a possibilidade de uma rede brasileira de IEA.

\section{Internacional}

A internacionalização esteve presente no $\mathrm{IEA}_{\mathrm{USP}}$ desde o início. Sempre recebemos pesquisadores internacionais para palestras ou eventos, convênios foram firmados com o Colégio do México, com o Collège de France, e com outras instituições, cátedras foram instaladas. O ciclo "Cinco séculos de presença francesa no Brasil", produzido em 2009 pelo Núcleo de Pesquisa Brasil-França ${ }^{27}$ (coordenador Gilberto Pinheiro Passos), é uma das iniciativas internacionais do IEA $_{\text {USP }}$ cujos textos serão publicados pela Edusp, em livro organizado por Leyla Perrone-Moisés.

Com o Colégio do México, realizará o projeto "Pesquisa urbana comparada: São Paulo e Cidade do México", coordenado por Martha Schteingart, do 
Colégio do México, e Camila D’Ottaviano, da FAU-USP. Maria Lígia Prado coordenou o convênio Colégio de México/IEA até meados deste ano.

O congresso "University-Based Institutes for Advanced Study in a Global Perspective: Promises, Challenges, New Frontiers", programado pelo Freiburg Institute for Advanced Studies (Frias), da Albert-Ludwigs-Universität Freiburg, representou um ponto importante de virada. Não pôde ser realizado em abril de 2010, a data inicialmente marcada, por conta da erupção do vulcão Eyjafjallajokull na Islândia, que paralisou aeroportos europeus. Cinquenta professores representando 32 IEA de vários países puderam finalmente reunir-se em Freiburg de 25 a 27 de outubro do mesmo ano. Da América Latina estavam Pedro Paulo Funari do CEAv e eu, representando o IEA $_{\text {Usp }}$.

Foi rica a experiência de interagir com colegas de lugares tão diferentes, tomava-se contato com a grande diversidade de estruturas e modos de funcionamento, mas também com uma unidade profunda de propósitos. Abordaram-se, nas sessões temáticas, os grandes temas: a escolha das áreas de atuação (Ciências Naturais e Técnicas, Ciências Sociais, Humanidades), a relação dos Institutos com a Universidade, a interdisciplinaridade, a criação de contextos de pesquisa produtivos, o financiamento e suas fontes nem sempre abundantes. A ênfase maior recaiu sobre o tema da cooperação entre Institutos de Estudos Avançados. Foi criado um steering committee, do qual faço parte, para cuidar das reuniões internacionais e do rumo da cooperação. Werner Frick, Carten Dose e outros colegas do Freiburg Institute for Advanced Studies fizeram um excelente trabalho, analisando o panorama mundial dos IEA, a partir das instituições participantes, apontando problemas, traçando as linhas de possível desenvolvimento. Do ponto de vista imediato, pudemos, como IEA $\mathrm{USP}_{\text {, }}$, estabelecer contatos que certamente trarão resultados em matéria de intercâmbio e cooperação.

Um desdobramento imediato da reunião de Freiburg foi a realização do encontro internacional "Social Sciences and Humanities meet the changing world: challenges, opportunities and frontiers", no Fudan Institute for Advanced Studies in the Social Sciences, da Universidade Fudan de Shangai (25 e 26 de junho de 2011), para o qual recebemos convite de Sujian Guo. Wagner Costa Ribeiro, do IEA ${ }_{\text {USP }}$, participou do encontro como o trabalho "International environmental policy and the emergence of new powers", que ele também apresentou no Institute for Advanced Humanistic Studies da Universidade de Pekin, a convite do diretor Tu Weiming. Renato Janine Ribeiro, do Conselho Deliberativo do IEA $\mathrm{USP}_{\text {, }}$, não pôde participar pessoalmente do encontro da Universidade de Fudan, mas terá o seu texto ("Other cultures come to the political fore") também publicado nos Anais do encontro.

Decisões positivas foram tomadas pelo steering committee, em sua reunião de Shangai. Werner Frick apresentou proposta para a organização de uma rede mundial de IEA com um site de internet locado em Freiburg e com um logo (com a sigla Ubias). O próximo encontro do steering committee será em Delhi, 
em 2012, e a próxima conferência internacional dos IEA será na Universidade de Johanesburgo, em 2013.

O IEA $_{\text {USP }}$ está num momento bom de expansão no sentido de sua inserção internacional. O apoio e a parceria da Vice-Reitoria Executiva para Relações Internacionais da USP serão essenciais para que esse desenvolvimento atinja a sua plenitude.

\section{Futuro}

As atividades de um IEA têm o charme da inovação e da não convencionalidade, e também, como é o caso do IEA $\mathrm{USP}_{\text {, }}$ do contato com as problemáticas sociais para as quais a ciência se sente tentada a contribuir. Um IEA representa um espaço especial, na Universidade, onde pode ser levada adiante a experimentação conceitual necessária a todo avanço do conhecimento e onde o encontro de perspectivas não é evento ocasional, mas sim a própria matriz de onde se originam as ideias novas. Há uma liberdade especial para explorar, mesmo saindo do caminho (mas a exploração não será sempre uma saída do caminho?) e também a compreensão de que os campos do saber, das artes e da ética se juntam em sínteses possíveis, acima das classificações. Essas motivações universitárias perenes encontram expressão e agitação (na expressão que empresto a um de meus colaboradores) num Instituto de Estudos Avançados.

Quis transmitir neste texto a imagem de um Instituto de Estudos Avançados ativo e variado, descobridor e reflexivo, incentivador de interfaces, acolhedor, em interação e participação constante com outros setores da Universidade, sensível ao social e ao que é melhor e o que é justo, preocupado com a excelência, interessado em ampliar a sua participação em redes, com outros Institutos, com outras instituições da sociedade, consciente da internacionalidade que cada vez mais se torna o panorama da ciência e da cultura porém centrado no seu contexto. Os 25 anos de existência honram o IEA ${ }_{\text {USP }}$, abrem o campo para desenvolvimentos muitos, que é possível, estrategicamente, antever e planejar.

Bem-vindos ao IEA.

Notas

1 Goddard, P. From the Director. Site do IEA de Princeton: <http://www.ias.edu/ about/from-the-director>.

2 Paula, J. A. A transdisciplinaridade e os desafios contemporâneos. Belo Horizonte: Editora da UFMG-Ieat, 2008.

3 Cruz, C. H. B.; Chaimovich, H. Brasil. Relatório Unesco sobre Ciência 2010. Disponível em: <http://unesdoc.unesco.org/images/0018/001898/189883por.pdf>. Acesso em: 12 out. 2011.

4 Sem ufanismo: a USP foi recentemente classificada em primeiro lugar na relação das principais Universidades latino-americanas (QS University Rankings: América Latina, Agência Fapesp. Disponível em: <http://agencia.fapesp.br/14582>). 
5 Nicolelis, M. (2011). Disponível em: <www.iea.USP.br/online/midiateca/neurociencia/index.html>.

6 Steiner, J. E. (2011). Disponível em: <www.iea.USP.br/online/midiateca/fisica/index.html>.

7 Albano, E. (2011). Disponível em: <www.iea.USP.br/online/midiateca/linguistica/ index.html>.

8 Pena, S. D. (2001). Disponível em: <www.iea.USP.br/online/midiateca/biologia/ index.html>.

9 Lent, R. (2011) Disponível em: <www.iea.USP.br/online/midiateca/biologia/index. html>.

10 Agradeço o empenho e as ideias de Eugênio Bucci no estudo inicial do novo formato do site.

11 Flexner, A. The usefulness of useless knowledge. Harper's Magazine, n.179, p.544-52, 1939.

12 Entrevista (não publicada) dada a Shozo Motoyama, IEA, 2011.

13 Nader, H. B.; Palis Jr., J.; Silva, J. A. A. Propostas e considerações da Sociedade Brasileira para o Progresso da Ciência (SBPC) e Academia Brasileira de Ciências (ABC) acerca da reforma do código florestal (plc 30/2011). Disponível em: <http://claudiodimauro. com.br/dimauro/userfiles/file/biblioteca/codigo_sbpc.pdf>.

14 A USP e a Sociedade: encontro com os Candidatos (2009). Disponível em: <http://www. iea.USP.br/online/midiateca/universidade>.

15 Marcovitch, J. Estudos avançados na Universidade. Estudos Avançados, 2011

16 Pela, S. K. Florestamento e reflorestamento no Brasil: uma análise do projeto Floram. São Paulo, 2010. Dissertação (Mestrado) - Faculdade de Administração, Economia e Contabilidade, Universidade de São Paulo.

17 Projeto-encomenda do CTAGRO/CNPq (processo n. 575069/2008-2).

18 Ribeiro, W. C.; Dias, J. P. S.; Sant'Anna Neto, J. L.; Zullo Jr., J. (2009). Disponível em: <www.iea.USP.br/iea/textos/climatechangeandsouthamerica.pdf>.

19 Sawaya, A. L. et al. Desnutrição, pobreza e sofrimento psíquico. São Paulo: Edusp, 2011.

20 Arbix, G. et al. (Org.) Inovação: estratégias de sete países. Série Cadernos da Indústria. Brasília, 2010. Disponível em: <www.iea.USP.br/iea/textos/inovacaoestrategiasdesetepaises.pdf>.

21 Codigo ambiental. Disponível em: <http://www.iea.USP.br/online/midiateca/ambiente/index.html>.

22 Colóquio 2010-2020: um Período Promissor para o Brasil? Disponível em: <www.iea. USP.br/iea/online/midiateca/futuro/index.html>.

23 São Paulo School of Advanced Studies in Speech Dynamics. Disponível em: <www.iea. USP.br/speechdynamics>.

24 Curso Filosofia e História da Ciência. Disponível em: <www.iea.USP.br/iea/online/ midiateca/filosofiadaciencia/index.html>.

25 A USP precisa mudar. Disponível em: <http://www.iea.USP.br/online/midiateca/ universidade>. 
26 Diversidade e integração na USP. Jornal da USP, jul. 2011.

27 Convênio IEA/Centre de Recherches sur le Brésil Contemporain da École Pratique des Hautes Études em Sciences Sociales.

César Ades é diretor do Instituto de Estudos Avançados da Universidade de São Paulo (IEA-USP) e professor titular da Instituto de Psicologia da USP. @ - cades@usp.br / cesarades@gmail.com

Recebido em 18.10.2011 e aceito em 21.10.2011. 